Published in "Global Ecology and Biogeography 19(3): 332-342, 2010"

which should be cited to refer to this work.

${ }^{1}$ UFZ Helmholtz Centre for Environmental Research, Department of Community Ecology, Theodor-Lieser-Strasse 4, D-06120 Halle (Saale), Germany, ${ }^{2}$ Ecology and Evolution Unit, Department of Biology, University of Fribourg, Chemin du Musée 10, CH-1700 Fribourg, Switzerland, ${ }^{3}$ Department of Ecology and Evolutionary Biology, Yale University, New Haven, CT 06520, USA, ${ }^{4}$ Community Ecology, Zoological Institute, University of Bern, Baltzerstrasse 6, CH-3012, Bern, Switzerland

${ }^{*}$ Correspondence: Marten Winter, UFZ Helmholtz Centre for Environmental Research, Department of Community Ecology, Theodor-Lieser-Strasse 4, D-06120 Halle (Saale), Germany.

E-mail: marten.winter@ufz.de

\section{The role of non-native plants and vertebrates in defining patterns of compositional dissimilarity within and across continents}

\author{
Marten Winter ${ }^{1,2 *}$, Ingolf Kühn ${ }^{1}$, Frank A. La Sorte ${ }^{3}$, Oliver Schweiger ${ }^{1}$, \\ Wolfgang Nentwig ${ }^{4}$ and Stefan Klotz ${ }^{1}$
}

\begin{abstract}
Aim Human activities have led to the spread and establishment of increasing numbers of non-native species. Here we assess whether non-native plant and vertebrate species have affected species compositions within and across Europe and North America. We also assess the effects of intra-continental species exchange using the example of vertebrates.
\end{abstract}

Location European countries and North America (states in the contiguous United States and provinces of Canada).

Methods We measured compositional dissimilarity of native and non-native assemblages of vascular plants and vertebrates and related these patterns to climatic dissimilarity and geographical distance. We considered three categories of nonnative species (introduced after AD 1500), namely: those (1) originating outside of both continents, (2) native to one continent and non-native to the other, and (3) native in a particular region of a continent but non-native in another region.

Results The presence of non-native plants and vertebrates led to more homogeneous species compositions between continents and to less homogeneous species composition within Europe compared with the native assemblages. In North America, the presence of non-native plants led to more homogeneous species compositions and the presence of non-native vertebrates had no effect. Species compositions being more homogeneous than the native composition were found for the three categories of non-native vertebrate species for both continents. Between continents, climate was a better predictor of compositional dissimilarity for non-native plants, whereas for vertebrates the explanatory power of climate and geographical distance were comparable. By contrast, within continents, climate was a better predictor of compositional dissimilarity of both plants and vertebrates.

Conclusions We found clear evidence for biotic homogenization as a consequence of species displacement. However, in relation to overall species richness this effect was rather small, indicating that floras and faunas are still quite distinct. Therefore, claiming that we already face homogeneous biotas might be premature, although clear indications are visible which should raise a note of caution, especially in the light of increasing globalization.

\section{Keywords}

Biotic homogenization, compositional dissimilarity, Europe, non-native species, North America, vascular plants, vertebrates. 


\section{INTRODUCTION}

'We must pull the plug on the global Waring blender of species...' (Kaufman, 1986, 37).

The discovery of the Americas by European explorers marked a new era in invasion biology defined by the drastic increase in global species interchange, particularly between North America and Europe (di Castri, 1989). The direction of interchange was virtually unidirectional, with species being introduced primarily from Europe to North America (Jäger, 1988; di Castri, 1989). In general, the types or pathways of introductions differ across taxa (Hulme et al., 2008): invertebrates and pathogens are often unintentionally introduced as contaminants or as stowaways while plants and vertebrates escape or are introduced intentionally. The longer the residence time after naturalization, the greater the potential for the introduced species to expand its range and become invasive (Rejmánek, 2000a; Richardson \& Pyšek, 2006). Species' naturalizations in the new environment are further facilitated in many cases by changes in land use (e.g. urbanization and agricultural development). One possible outcome of the successful introductions of non-native species is the increased similarity (i.e. decreased dissimilarity $=$ decline in beta diversity) of species composition across space, an outcome often referred to as biotic or taxonomic homogenization (McKinney \& Lockwood, 1999).

Scale dependences are well known for biodiversity patterns in general (e.g. Whittaker et al., 2001) and invasion processes in particular (e.g. Rouget \& Richardson, 2003; Kühn \& Klotz, 2007). Sax \& Gaines (2003) gave many examples where, at local and regional scales, naturalizations outpaced extirpations and overall species richness increased. However, if proportionately more non-native species develop widespread distributions, this could result in biotic homogenization. Invasion (or the invasion process) in this context does not mean a specific step but the complete process from introduction to becoming invasive (Richardson et al., 2000; Pyšek et al., 2004). Although several terms are used in the context of global species homogenization, such as 'New Pangaea' and 'Homogocene' (Rosenzweig, 2001; McKinney, 2005), most studies focus on continental or smaller scales (e.g. plants: Rejmánek, 2000b; McKinney \& Lockwood, 2001; Rooney et al., 2004; Qian \& Ricklefs, 2006; Castro \& Jaksic, 2008; fishes: Olden \& Poff, 2004; Leprieur et al., 2008; birds: La Sorte \& Boecklen, 2005; Van Turnhout et al., 2007). We are only aware of one cross-continental approach - an analysis of urban floras within North America and Europe (La Sorte et al., 2007). In addition, only a few studies have addressed these issues for multiple taxa (e.g. birds and butterflies: Blair, 2001; plants and fishes: McKinney, 2005; plants and vertebrates: Olden et al., 2006).

Here, we analyse broad-scale patterns of compositional dissimilarity for vascular plant and vertebrate species within and between North America and Europe at the resolution of states in the contiguous United States and provinces of Canada and countries in Europe. We hypothesize that the spread of non-native species has resulted in more similar species compositions within and between continents for vascular plants and vertebrates.

\section{MATERIALS AND METHODS}

\section{Species data}

We collated species lists by states and provinces in North America and by countries in Europe. We compiled all varieties and subspecies within the lists into single species for analysis. For both taxa we applied commonly accepted nomenclatures with synonymies. All species names (including synonymies) were cross-checked for redundancies. Flora Europaea was the standard for plant data and Fauna Europaea for vertebrate data. Data for non-native European vertebrates were very recently published by the DAISIE Consortium (Delivering alien invasive species inventories for Europe; DAISIE, 2009) and therefore comparable to regularly updated North American data. Vertebrates are generally well investigated and thus sampling effort is comparably high across North America and Europe. Our European plant data are generally older than the North American data and therefore reflect an earlier stage of the introduction and dispersal process for non-native plant species. However, plants are usually less well recorded, with larger regional differences in sampling effort, but the quality of the data are still sufficient for comparisons at coarse scales such as country or state checklists.

The North American part of the study area includes states in the contiguous United States and provinces of Canada. The European part of the study area is defined by regions used in Flora Europaea (Tutin et al., 1964-1980) and by regions used in Fauna Europaea Web Service (2004). The geographical delineation differs only slightly between the plant and vertebrate databases (see Figs S1 \& S2 in Appendix S1 in the Supporting Information). Islands were excluded when the data allowed for a distinction between mainland and island species assemblages (see Appendix S1). Islands, in most cases, represent isolated ecosystems where invasion processes act differently compared with the mainland (Lonsdale, 1999).

North American plant species lists for states and provinces and whether a species is native or non-native to a certain region (hereafter referred to as origin status) were compiled from the Kartesz database (Kartesz, 1999). European plant species lists for each country were compiled from the European Science Foundation European Documentation System (ESFEDS) database based on Flora Europaea (Tutin et al., 1964-1980). After combining both databases we had a total of 90 political regions $(60$ North American states and provinces and 30 European countries). The North American plant database did not provide information on species origin status by state or province and we did not have access to all state or provincial databases. We could hence only recognize origin status on the continental level (i.e. only plants originating outside North America were identified as non-natives). To be consistent in our classification across North America and Europe, we reclassified origin status of the European database at continental extent.

North American vertebrate distribution and origin status by state and province was provided by NatureServe (2007). European vertebrate distribution data were provided by the Fauna Europaea Web Service (2004). After combining both databases, 
we had 98 political regions (61 North American states and provinces and 37 European countries). Fauna Europaea does not include data on marine or domesticated species, which were thus not considered in this study. The data on origin status of European vertebrates were compiled at species level mainly from the DAISIE database (DAISIE, 2007), Fishbase (http:// www.fishbase.org/), Birdlife (http://www.birdlife.org/) or Jeschke \& Strayer (2005) and were afterwards checked by experts from the DAISIE Consortium (DAISIE 2007).

Native species were defined as species that occurred in North America or Europe before the European discovery of the Americas (see Pyšek et al., 2004). Hence, European archaeophytes (non-native species introduced before the European discovery of the Americas) were considered as natives in Europe. It is important to note that European archaeophytes are primarily identified as non-native in North America (La Sorte \& Pyšek, 2009). We classified non-native species (sensu Pyšek et al., 2004; here, introduced and successfully established after the European discovery of the Americas) into three categories: those (1) originating outside both North America and Europe (global nonnatives); (2) being native in one continent and non-native in the other (continental non-natives); and (3) being native in a region of the continent but non-native in another (regional nonnatives). Note that global and regional non-natives could occur in both continents or only in one. The third category was only available for vertebrates.

\section{Climate data and geographical distances}

Climate data with a resolution of 2.5 arcmin were obtained from the Worldclim data set (Hijmans et al., 2005). We included annual temperature and precipitation, maximum temperature of the warmest month, minimum temperature of the coldest month, precipitation and temperature seasonality and mean monthly precipitation. We chose these variables because of their ecological importance for the distribution and life cycles of plants and vertebrates (Araújo et al., 2005; Thuiller et al., 2005; Levinsky et al., 2007; Pompe et al., 2008). To minimize problems resulting from multicollinearity, we performed a cluster analysis with all 18 variables using a threshold of $r=0.7$. This resulted in five climatic variables: maximum temperature of the warmest month, minimum temperature of the coldest month, precipitation seasonality and precipitation of July and January. Each climatic variable was standardized to zero mean and unit variance over all grid cells and their mean values calculated per region. Climatic dissimilarities between regions were estimated using Euclidean distance of the average values. Geographical distances between regions were estimated using centroid distances.

Broad-scale distributional data for native, and particularly non-native, species are typically compiled within political regions. Using political boundaries while ignoring natural geographical features may introduce a bias (Olden, 2006). However, when political boundaries encompass more than one biogeographical region, species numbers would be artificially high. So many species in turn would lead to an underestimation of homogenization instead of overestimating it (Olden, 2006). Thus, our conclusions about homogenization are rather conservative and actual continent-wide homogenization might be even larger.

Olden \& Rooney (2006) discuss the limited explanatory power associated with the use of extant species pools and suggest analysing compositional patterns temporally. Nevertheless, we used a 'space for time' approach to analyse compositional patterns due to the lack of temporal data and because spatial patterns also reflect temporal processes (Fukami \& Wardle, 2005). The main assumption of the space-for-time substitution is that there is congruence between spatial and temporal patterns (Pickett, 1989). By estimating compositional differences for all species and those of native species we compared two temporal scenarios: (1) the species composition of an 'original flora' (natives only) and (2) a current flora, changed due to introductions (all species $=$ natives + non-natives). Data on extinct species were not included because this information is scarce and not available for all regions. Recently compiled data on national extinctions of plants in Europe showed that the number of extinct or locally extirpated species in European countries was on average a tenth of those associated with nonnative species (M. Winter et al., unpublished data). The effect of the loss of native species on compositional patterns is likely to be superseded by the introduction of many more non-native species. Qian \& Ricklefs (2006) suggest that species extirpations only played a minor role in defining compositional patterns for North American state floras due to their low numbers.

\section{Statistical analysis}

To assess dissimilarity of species composition between regions we calculated the $\beta_{\text {sim }}$ index of dissimilarity. The $\beta_{\text {sim }}$ dissimilarity index is relatively unaffected by gradients of species richness (Koleff et al., 2003), which tend to be pronounced between native and non-native species assemblages within regional floras. The index ranges from 0 to 1 , absolute similarity to absolute dissimilarity, and is calculated as $1-[\min (b, c) /(a+\min (b$, $c)$ )], where $a$ is the number of species shared, $b$ is the number unique to the first assemblage, and $c$ is the number unique to the second assemblage.

We analysed the relative effects of geographical and climatic distance on species dissimilarities using variance partitioning (Manly, 1991; Legendre \& Legendre, 1998). We partitioned the overall explained variance into components of independent (I) and joint $(\mathrm{J})$ effects of geographical distance and climatic dissimilarity, respectively.

We calculated the $\beta_{\text {sim }}$ dissimilarity for native and non-native species and all species combined for each unique pairwise combination of regions within and between continents. The contribution of non-native species to the overall dissimilarity was calculated as the difference between the $\beta_{\text {sim }}$ dissimilarity of all species and that of native species. The relative contribution of non-native species to the overall dissimilarity was calculated as the median percentage of the difference in dissimilarity estimated for native and non-native species per region. The 

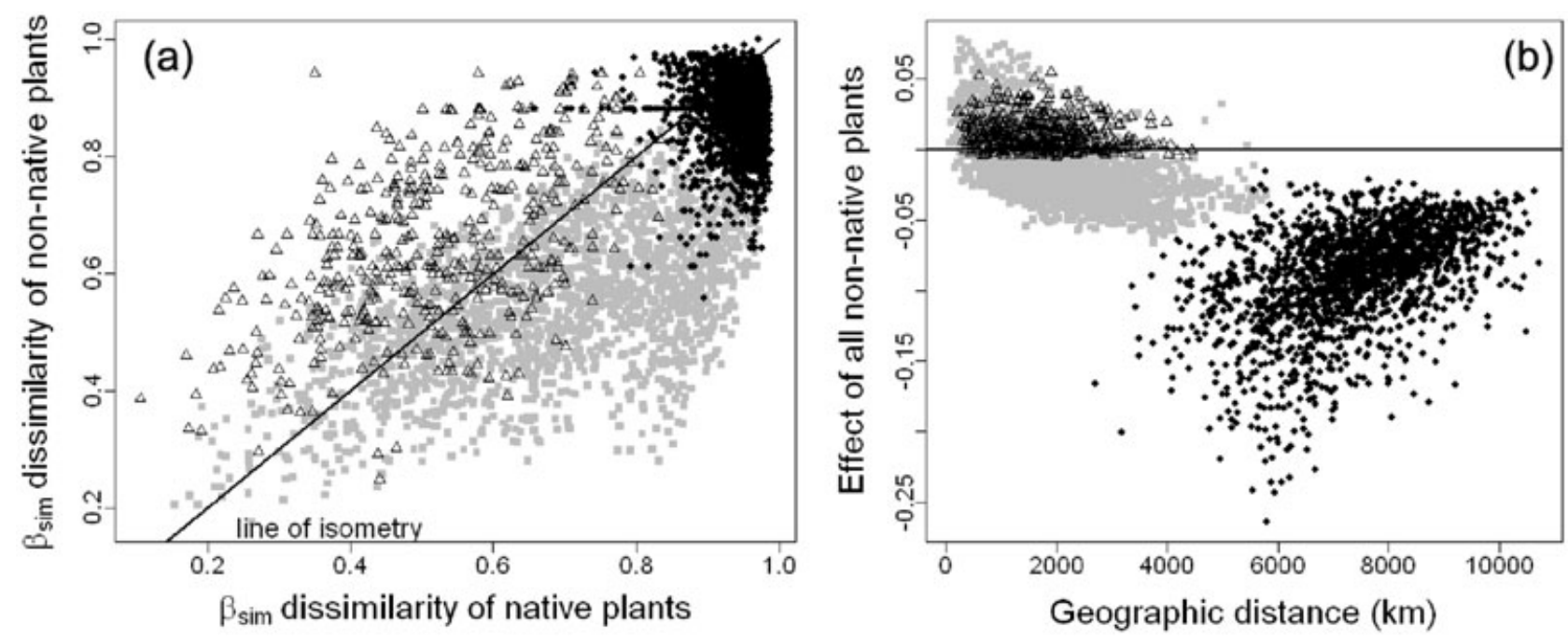

Figure 1 (a) $\beta_{\text {sim }}$ dissimilarity of non-native plant species assemblages versus dissimilarity of native species assemblages. Points represent pair-wise dissimilarities between regions, namely: black points, cross-continental comparisons between North American and European regions; grey squares, North American regions; open triangles, European regions. Values above the isometric line indicate higher dissimilarity of non-native plants across regions (i.e. countries, states, provinces) compared with native plants (potential differentiation), while values below the isometric line indicate the opposite (negative dissimilarity, i.e. higher similarity of non-native plant compared with native plants; potential homogenization). Non-native plants across both continents and within North America are more similar (as indicated by negative dissimilarity) than native plants (values below the isometric line; Fisher paired comparison test, $P<0.0001$ ).

Non-native plants within Europe are more dissimilar than native plants (values above the isometric line; Fisher paired comparison test, $P<$ 0.0001). (b) Contribution of all non-native plant species to overall dissimilarity (difference of $\beta_{\text {sim }}$ dissimilarity of all and native species) in relation to geographical distance (symbols as above). Non-native plant species across both continents and in North America lead to homogenization (negative values, Fisher paired comparison test, $P<0.0001$ ). Non-native plant species in Europe lead to differentiation (positive values, Fisher paired comparison test, $P<0.0001$ ).

remaining effect (see Figs $1 \mathrm{~b} \& 2 \mathrm{~b}$ ) of the different direct comparisons of non-native and native species can have two sources. Firstly, continental non-native species across continents can have different origin states in the different continents (being native in one continent but non-native in the other). Secondly, regional non-native species within continents can be native in one region but non-native in the other. Since regional comparisons are based on dissimilarity matrices (which are built up of non-independent data points) we used for all analyses a permutation test (1000 permutations) on the F-statistics of each of the predictors of a multiple regression model. This is comparable to a pairwise Mantel test with multiple predictors. Gains or losses in compositional dissimilarities were assessed using deviations of the dissimilarity values from zero and Fisher's paired comparison test. Differences in species numbers were tested with a Welch's two-sample $t$-test for samples with unequal variance (Welch, 1938). This test yields fractional degrees of freedom. All calculations were performed in $\mathrm{R}$ (version 2.6; R Development Core Team, 2007).

\section{RESULTS}

The final data set contained 18,643 plant species in North America (15,482 native and 3161 non-native), 10,635 plant species in Europe (9759 native and 876 non-native), 2627 vertebrate species in North America (2266 native and 361 non-native) and 1488 vertebrate species in Europe (1344 native and 144 non-native). North American states and provinces contain on average $20.3 \pm 5.8 \%$ (mean \pm standard deviation) non-native plant species and $5.6 \pm 2.8 \%$ non-native vertebrate species. European regions have on average $5.1 \pm 2.0 \%$ fewer non-native plant species ( $t$-test, d.f. $=80.6, t=-13, P<0.001$ ) and $3.7 \pm 1.2 \%$ fewer non-native vertebrate species $(t$-test, d.f. $=$ 92.9, $t=-3.9, P<0.0001)$. Among plants, unbalanced species exchange was evident between the two continents with 1276 European plants identified as non-native in North America but only 214 North American identified as non-native in Europe (for more details see Table S1 in Appendix S2).

\section{Plants}

Dissimilarities of floras increase linearly across all regions with increasing log-transformed geographical distance (single model, $R^{2}=0.69, P<0.05$ ) and climatic dissimilarity (single model, $R^{2}$ $=0.36, P<0.05$; Fig. S3 in Appendix S2). Within and between continents, geographical distance explained more of the overall variance of species dissimilarity per region than climatic distance (Fig. S3 in Appendix S2, $R_{\text {overall }}^{2}=0.75$; variance partitioning, $\left.I_{\text {distance }}=0.52, I_{\text {climate }}=0.20\right)$. Patterns of non-native and native species assemblages differed in such a way that: (1) explained variance in dissimilarity among non-native species assemblages was always smaller than among native species; 

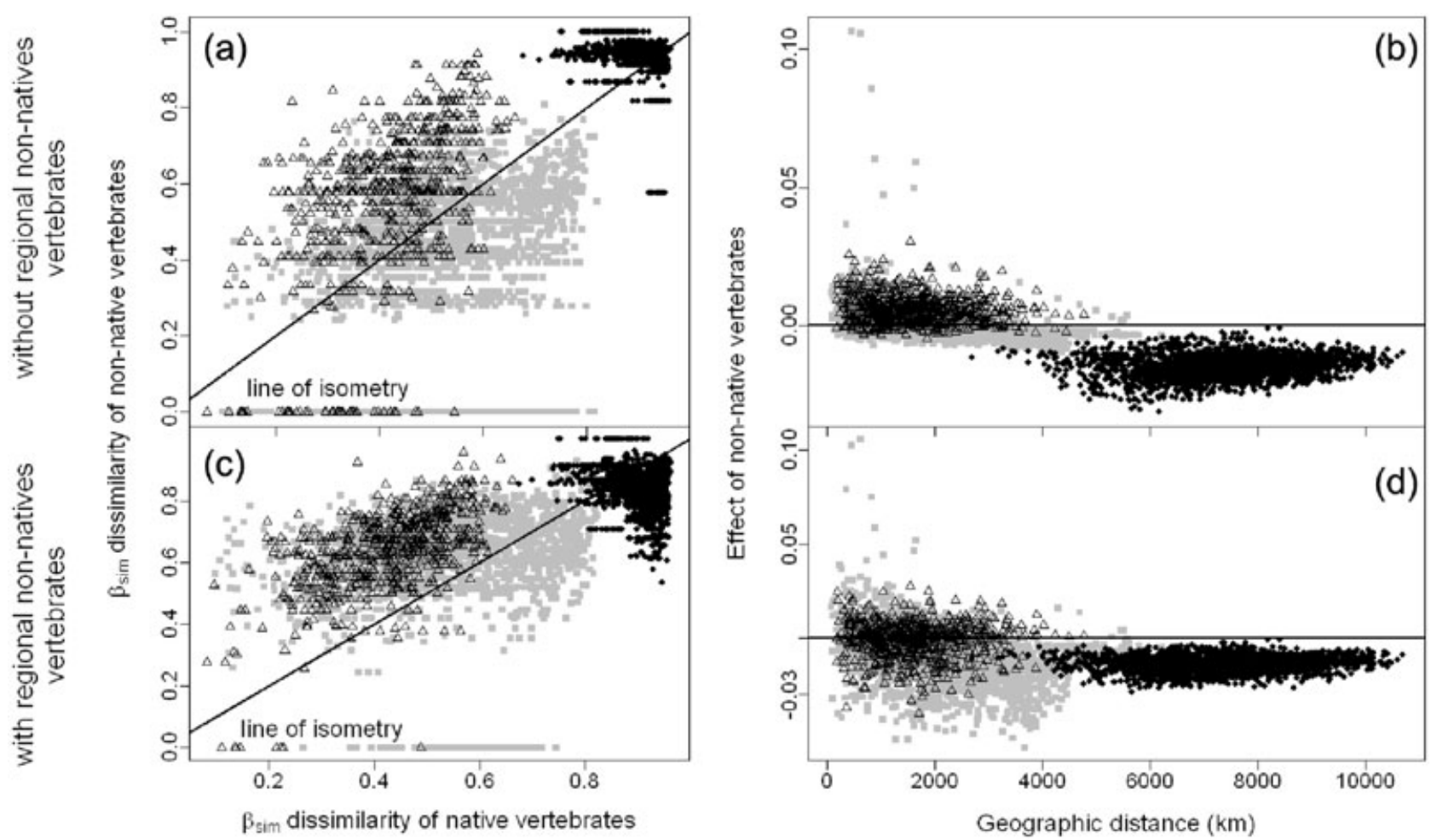

Figure 2 (a) $\beta_{\text {sim }}$ dissimilarity of non-native vertebrate assemblages versus dissimilarity of native vertebrate assemblages. Points represent pair-wise dissimilarities between regions, namely: black points, cross-continental comparisons between North American and European regions; grey squares, North American regions; open triangles, European regions (symbols consistent through panels). Values above the isometric line indicate higher dissimilarity of non-native vertebrates across regions (i.e. countries, states, provinces) compared with native vertebrates (potential differentiation), while values below the isometric line indicate the opposite (negative dissimilarity, i.e. higher similarity of non-native plants compared with native plants; potential homogenization). Non-native vertebrates across both continents and within Europe lead to differentiation (values above the isometric line; Fisher paired comparison test, $P<0.0001$ ). Non-native vertebrates in North America lead to homogenization (values below the isometric line; Fisher paired comparison test, $P<0.0001$ ). (b) Contribution of all non-native vertebrate species to overall dissimilarity (difference of $\beta_{\text {sim }}$ dissimilarity of all and native species) in relation to geographical distance. Non-native vertebrates across both continents lead to homogenization (negative values; Fisher paired comparison test, $P<$ 0.0001). Non-native vertebrates in Europe lead to differentiation (positive values; Fisher paired comparison test, $P<0.0001$ ). There is no significant pattern in North America. (c, d) As above but considering regional non-natives (i.e. using a different concept of origin status than for plants). (c) Non-native vertebrates across both continents lead to homogenization (values below the isometric line; Fisher paired comparison test, $P<0.0001$ ). Non-native vertebrates within Europe and North America lead to differentiation (values above the isometric line; Fisher paired comparison test, $P<0.0001$ ). (d) Non-native vertebrate species within North America, Europe and across both continents lead to homogenization (negative values; Fisher paired comparison test, $P<0.0001$ ).

(2) between continents, the dissimilarity of non-native species was best explained by climate, whereas geographical distance explained most of the variance of dissimilarity of native species; (3) within continents the dissimilarity of non-native species assemblages in North America was highly determined by climate, while contrastingly geographical distance was more important for the dissimilarity of non-native species assemblages in Europe; and (4) climate and geographical distance contributed evenly to explain the dissimilarity of natives species assemblages in both continents (c. 30\%; see Table 1).

Between continents, global non-natives yielded homogenization in almost all comparisons among regions (Fig. 1a). As long as only non-native floras are compared between continents, only global non-natives occurring in both continents can by definition lead to homogenization. However, when comparing the contribution of non-natives to overall dissimilarity, it is possible to consider the potential homogenization effect of continental non-natives, too. In doing so, we found that in cases where global non-natives did not lead to homogenization, the additional effect of continental non-natives resulted in more similar species compositions (cf. Fig. 1a,b). With increasing geographical distance the homogenizing effect of all non-native species among continents decreased (see Fig. 1b; single model, $R^{2}=0.23$ ).

In Europe, differentiation of species composition was indicated by highly dissimilar compositions of non-natives, while the effect of global and continental non-natives could not be disentangled (Fig. 1a). This pattern was robust when the contribution of non-natives on overall dissimilarity was taken into account (Fig. 1b; results remained similar with climatic distance 
Table 1 Results of variance partitioning (presented as proportions of independent effects) of species dissimilarities as a function of distance and climate within and between North-America and Europe for plants and vertebrates.

\begin{tabular}{|c|c|c|c|c|c|}
\hline & & & $R_{\text {overall }}^{2}$ & $I_{\text {distance }}$ & $I_{\text {climate }}$ \\
\hline \multirow[t]{6}{*}{ Natives } & Plants & Between continents & 0.43 & 0.90 & 0.09 \\
\hline & & Within North America & 0.66 & 0.30 & 0.33 \\
\hline & & Within Europe & 0.33 & 0.38 & 0.29 \\
\hline & Vertebrates & Between continents & 0.66 & 1.00 & 0.00 \\
\hline & & Within North America & 0.50 & 0.34 & 0.25 \\
\hline & & Within Europe & 0.43 & 0.42 & 0.26 \\
\hline \multirow[t]{6}{*}{ Non-natives } & Plants & Between continents & 0.12 & 0.36 & 0.71 \\
\hline & & Within North America & 0.22 & 0.14 & 0.58 \\
\hline & & Within Europe & 0.32 & 0.41 & 0.26 \\
\hline & Vertebrates & Between continents & 0.10 & 0.83 & 0.24 \\
\hline & & Within North America & 0.04 & 0.92 & 0.17 \\
\hline & & Within Europe & 0.24 & 0.40 & 0.26 \\
\hline
\end{tabular}

$I_{\text {distance, }}$ independent effect of geographical distance, based on centroid distances between regions in $\mathrm{km}$. $I_{\text {climate, }}$, independent effect of climatic dissimilarity, based on Euclidean distance of five averaged, standardized climatic variables (see Materials and Methods for details). All results are highly significant $(P<0.001)$. Note that the summed values of independent effects do not necessarily equal 1 due to potentially negative joint effects (not displayed). as the predictor). The effect of continental non-natives with different origin status (being native in one continent and nonnative in the other) also contributed to the difference in the dissimilarities of all species.

By contrast, in North America, homogenization resulted from low dissimilarity among non-native plant assemblages (Fig. 1a). This pattern did not change when taking the effect of nonnatives on the overall dissimilarity into account (Fig. 1b; results remain similar with climatic distance as the predictor). To test whether the continent-wide spatial distribution differed between native and non-native plants, we compared the regression slopes obtained from the regional comparisons (Fig. S4 in Appendix S2). The homogenization of the North American flora was promoted by the more homogeneous spatial distribution of non-native plants compared with native plant species (shallower slope of the regression line in Fig. S4 in Appendix S2; $P<0.001)$. In the European flora, we found no difference in the spatial distribution of native and non-native plant species.

The relative contribution of non-native plant species on the overall dissimilarity varies between continents and scales but is generally very small (North America $3.1 \pm 2.6 \%$; Europe $1.7 \pm$ 3.0\%; Europe versus North America 9.6 \pm 5.5\%).

\section{Vertebrates}

Within and between continents, geographical distance explained most of the overall variance of species dissimilarity among regions (Fig. S5 in Appendix S2; $R_{\text {overall }}^{2}=0.86$, variance partitioning, $\left.I_{\text {distance }}=0.78, I_{\text {climate }}=0.07\right)$. Between continents, climatic dissimilarity had no explanatory power (Appendix S2, Fig. S5, $R^{2}=0.67$, variance partitioning, $I_{\text {distance }}=1.00, I_{\text {climate }}=0$ ). However, within continents, dissimilarities of regional faunas were equally well explained by climatic dissimilarity and geographical distance (Fig. S5 in Appendix S2, $R^{2}=0.61$, variance partitioning, $I_{\text {distance }}=0.30, I_{\text {climate }}=0.31$ ). Similar to patterns observed for plants: (1) the explained variance in the dissimilarity of non-native vertebrate species assemblages was always smaller than those of native species assemblages; (2) between continents, the variance in the dissimilarity of native species assemblages was explained almost exclusively by geographical distance; (3) within North America, climate and geographical distance explained the dissimilarity of native vertebrates almost equally well; and (4) within Europe the dissimilarity of natives and non-native assemblages was better explained by geographical distance. Unlike plants, between continents and within North America, geographical distance explained most of the overall variance of dissimilarity among non-native assemblages. When considering both global and continental non-natives (i.e. not considering regional non-natives), the results were similar to those for plants: differentiation in Europe, and a tendency for homogenization in North America and between continents (Fig. 2b). Although, across continents global non-native vertebrates had a strong differentiation effect (Fig. 2a), the pattern changed completely to homogenization when the contribution of continental non-natives to overall dissimilarity was taken into account (Fig. 2b; results were similar with climatic distance as the predictor).

When the additional effects of regional non-natives were taken into consideration, the patterns changed, mainly within continents. As before, across continents non-native vertebrates led to homogenization (Fig. 2c,d). Within continents, the comparison of results considering and ignoring regional non-natives showed that regional non-natives had a strong homogenization effect (cf. Fig. 2b,d). Although differentiation was indicated mainly by higher dissimilarity of all non-native assemblages in both continents, regional non-native assemblages yielded homogenization (cf. Fig. 2c,d; results were similar with climatic dissimilarity as the predictor).

The relative contribution of non-native vertebrates to the overall dissimilarity varies between continents and scales but is 
generally very small (not considering regional non-natives: North America $0.5 \pm 1.3 \%$; Europe $1.2 \pm 1.6 \%$; Europe versus North America $1.6 \pm 0.5 \%$; considering regional nonnatives: North America $2.2 \pm 2.3 \%$; Europe $1.3 \pm 2.2 \%$; Europe versus North America $1.5 \pm 0.5 \%$ ).

\section{DISCUSSION}

\section{Between continents}

Between continents we found a consistent homogenization effect of non-native species for both plants and vertebrates. Evidence for cross-continental homogenization for plants within urban areas was shown by La Sorte et al. (2007). Here we demonstrate that this pattern is consistent at a continental extent. Our results suggest a more dominant role for global non-natives in homogenizing floras across the continents.

As far as we are aware, we are the first to show intercontinental homogenization for vertebrates due to non-native species. Nonnative vertebrates are likely to be widespread within each continent, which would promote greater similarity between continents. Jeschke \& Strayer (2005) showed that once North American or European vertebrates are introduced to the other continent, they have a high potential to become naturalized and spread thus leading to homogenization between continents.

\section{Within continents}

Human activities introduce species through multiple different pathways and often in a haphazard fashion (Hulme et al., 2008). This process can result in the differentiation of species composition across space (Qian \& Ricklefs, 2006; Qian et al., 2008). However, if given enough time, introduced species can become invasive and expand their distributions (Kowarik, 1995; Williamson et al., 2009) and homogenization of species composition across space can become more likely. Consequently, one could conjecture that the differentiation patterns observed in Europe are due to a dominance of recently introduced species that have not had enough time to spread, and the homogenization patterns observed in North America are due to introductions in the more distant past. Such mechanisms of time-dependent probability of spread (Pyšek \& Jarošík, 2005; Williamson et al., 2009) seem reasonable for the effects of translocated plants and vertebrates in Europe.

Introductions were initially unidirectional, where European settlers intentionally and unintentionally introduced new species especially to the New World before introducing species back into Europe much later in considerable numbers (Crosby, 1986; di Castri, 1989; Simberloff, 1989; Lonsdale, 1999). Europe was faced with human land-use and environmental changes for much longer than most of the regions world-wide colonized by Europeans. Therefore, species originating in those regions being introduced in Europe were at disadvantage in terms of competition and establishment (Jäger, 1988; Fox, 1990; Niemelä \& Mattson, 1996; Forman, 2003). This is probably one of the reasons for the observed homogenization in North America and differentiation in Europe. This is supported by a flatter distancedecay function for dissimilarities of non-native plants compared with native plants in North America. In Europe, on the other hand, the slopes of the distance-decay functions of non-native plants and native plants do not differ from each other. Yet an overall higher dissimilarity of non-native species led to general differentiation, indicating a haphazard distribution of nonnative species due to human influence and therefore an earlier stage of the invasion process than in North America.

However, these patterns are likely to be affected by: (1) the presence of European archaeophytes among European natives and North American non-native plant species, and (2) differences in historical human movements and flows of commercial goods within the continents. Archaeophytes co-evolved in Europe with anthropogenic land-use change long before the discovery of the Americas, and spread with human migration. As a consequence of their strong association with human agricultural activities, they are more homogeneously distributed across space (Kühn et al., 2003; La Sorte \& Pyšek, 2009). La Sorte \& Pyšek (2009) found European archaeophytes, when contrasted with other non-native plant species, to be more widespread and associated with losses in beta diversity among state floras in the United States. This indicates that the pattern of homogenization in North America observed in this study for non-native species is probably driven by the early introductions of European archaeophytes into North America. The pattern of differentiation for non-natives in Europe is therefore a consequence of more recent introductions (Pyšek \& Jarošík, 2005). A similar effect for archaeophytes was found for urban areas in Europe (Kühn \& Klotz, 2006; La Sorte et al., 2008).

The similar spatial distributions of native and non-native plants in Europe could partly originate in its politically highly diverse structure compared with North America. Antagonistic political systems historically have prevented continent-wide migration or trade. Thus, not only a lack of time but also trade barriers might have impeded the introduction of non-native species by humans across the European continent. Similarly to our analysis, Castro \& Jaksic (2008) found no differences in floristic similarity of non-native and native plants among Chilean regions as a result of similar spatial distribution of native and non-native plants. They discussed the biogeographical differences in the Northern and Southern Hemispheres suggesting that latitudinal more than longitudinal constraints affect the beta-diversity pattern in Chile in particular and in South America in general. However, an artificial increase in the geographical distribution of naturalized plants did result in floristic homogenization. This could also indicate an earlier stage of invasion process than we observed in North America, for example.

\section{Effects of regional non-native vertebrates}

When comparing patterns of regional non-natives with those that excluded regional non-natives, we found a homogenization effect between and within continents. Regional non-native 
vertebrates seem to be homogeneously distributed within the continents and play a dominant role in homogenizing continental vertebrate faunas. Leprieur et al. (2008) showed that regional non-native fishes were associated with homogenization within 12 North American states and 25 major European water basins. McKinney (2005) demonstrated a greater homogenizing effect of regional non-native plant species introduced into the United States from nearby sources than of those from more distant regions, comparable to global non-natives used in the present study.

\section{Effects of climate \& distance}

A positive relationship between geographical distance and species dissimilarities is often caused by underlying factors such as climatic suitability (e.g. Soininen et al., 2007) or migration and dispersal processes. Rejmánek (2000a), Qian \& Ricklefs (2006) and Qian et al. (2008) found a differentiation effect of non-native plant species amongst the floras of neighbouring North American areas, but a homogenization (or decreased differentiation) effect amongst floras at greater distance. We also found a trend in North America that, with increasing geographical distance, non-native species contributed to the homogenization of floras, whereas across continents, with increasing geographical distance, homogenization of non-native species decreased. This pattern could result from human settlement history between North America and Europe since AD 1500, which started mostly in western Europe (England, France, Spain and Portugal) and continued in North America and primarily from east to west (Clemants \& Moore, 2003). Generally, weaker overall models of non-native plant assemblages probably reflect more incidental distributions of those species and suggest that non-native species have not reached their ecological equilibrium (e.g. Williamson et al., 2005).

For centuries species were transported by humans independent of climate into new regions across large geographical distances. Nevertheless, climatic dissimilarities of native and invaded ranges remained strong predictors of successful establishment and spread. The strong effect of climate on dissimilarity of non-native plant species between continents reinforces our expectation that climatic suitability is more important for the successful establishment of non-native species between continents than geographical distance between regions of different continents.

\section{Conclusions}

In summary, our results show that we have the initial signs of a global homogenization of floras and vertebrate faunas due to the introduction, establishment and spread of non-native species. At a regional scale, historical aspects widen the general pattern to a more complex system and lead to differentiation among European vertebrate faunas and floras. In addition, our findings of the homogenization effect of regional non-natives show that scale-dependent effects and the impact of different origin status need to be considered. However, the relatively small effect of non-native species on overall dissimilarity indicates that floras and faunas are still quite distinct. Therefore, care has to be taken when claiming that we are facing a Homogocene, but clear indications in that direction are already visible and might become increasingly relevant, especially in the face of increasing globalization (Lambdon et al., 2008). We presume that with an ongoing spread of non-native species, recent heterogeneous distributions in Europe will diminish and homogenization effects of non-native species will increase.

\section{ACKNOWLEDGEMENTS}

The authors are grateful to Richard Pankhurst (ESFEDS) for providing data from Flora Europaea, to Yde de Yong and the Fauna Europaea team for providing European animal data, and to the DAISIE consortium, especially Francesca Gherardi, François Chiron, Riccardo Scalera and Katja Popoljsaj, for providing and checking data for non-native European vertebrates. We also thank Jan Hanspach, David Currie, Erica Fleishman and three anonymous referees for their valuable comments. The authors were partly funded by the European Union through the FP 6 projects DAISIE (DAISIE, 2009) project no. SSPI-CT-2003511202 and ALARM (GOCE-CT-2003-506675; Settele et al., 2005).

\section{REFERENCES}

Araújo, M.B., Pearson, R.G., Thuiller, W. \& Erhard, M. (2005) Validation of species-climate impact models under climate change. Global Change Biology, 11, 1504-1513.

Blair, R.B. (2001) Birds and butterflies along urban gradients in two ecoregions of the United States: is urbanization creating a homogeneous fauna? Biotic homogenization (ed. by J.L. Lockwood and M.L. McKinney), pp. 33-56. Kluwer Academic/ Plenum Publishers, New York.

di Castri, F. (1989) History of biological invasions with special emphasis on the Old World. Biological invasions: a global perspective (Scope 37) (ed. by J.A. Drake, H.A. Mooney, F. Di Castri, R.H. Groves, F.J. Kruger, M. Rejmánek and M. Williamson), pp. 1-30. Wiley, New York.

Castro, S.A. \& Jaksic, F.M. (2008) How general are global trends in biotic homogenization? Floristic tracking in Chile, South America. Global Ecology and Biogeography, 17, 524-531.

Clemants, S. \& Moore, G. (2003) Patterns of species richness in eight northeastern United States cities. Urban Habitats, 1, 4-16.

Crosby, A.W. (1986) Ecological imperialism: the biological expansion of Europe, 900-1900. Cambridge University Press, New York.

DAISIE (2007) Delivering alien invasive species inventories for Europe. Available at: http://www.europe-aliens.org/.

DAISIE (2009) Handbook of alien species in Europe. Springer, Dordrecht.

Fauna Europaea Web Service (2004) Fauna Europaea, version 1.1. Available at: http://www.faunaeur.org/ (accessed 17 April 2008). 
Forman, J. (2003) The introduction of American plant species into Europe: issues and consequences. Plant invasions: ecological threats and management solutions (ed. by L. Child, J.H. Brock, G. Brundu, K. Prach, P. Pyšek, P.M. Wade and M. Williamson), pp. 17-39. Backhuys Publishers, Leiden.

Fox, M.D. (1990) Mediterranean weeds: exchanges of invasive plants between the five Mediterranean regions of the world. Biological invasions in Europe and the Mediterranean basin (ed. by F. Di Castri, A.J. Hansen and M. Debussche), pp. 179-200. Kluwer Academic, Dordrecht, The Netherlands.

Fukami, T. \& Wardle, D.A. (2005) Long-term ecological dynamics: reciprocal insights from natural and anthropogenic gradients. Proceedings of the Royal Society Series B: Biological Sciences, 272, 2105-2115.

Hijmans, R.J., Cameron, S.E., Parra, J.L., Jones, P.G. \& Jarvis, A. (2005) Very high resolution interpolated climate surfaces for global land areas. International Journal of Climatology, 25, 1965-1978.

Hulme, P.E., Bacher, S., Kenis, M., Klotz, S., Kühn, I., Minchin, D., Nentwig, W., Olenin, S., Panov, V., Pergl, J., Pyšek, P., Roques, A., Sol, D., Solarz, W. \& Vila, M. (2008) Grasping at the routes of biological invasions: a framework for integrating pathways into policy. Journal of Applied Ecology, 45, 403-414.

Jäger, E.J. (1988) Möglichkeiten der Prognose synanthroper Pflanzenausbreitungen. Flora, 180, 101-131.

Jeschke, J.M. \& Strayer, D.L. (2005) Invasion success of vertebrates in Europe and North America. Proceedings of the National Academy of Sciences USA, 102, 7198-7202.

Kartesz, J.T. (1999) A synonymized checklist and atlas with biological attributes for the vascular flora of the United States, Canada, and Greenland. North Carolina Botanical Garden, Chapel Hill, NC.

Kaufman, L. (1986) Why the ark is sinking. The last extinction (ed. by L. Kaufman and K. Mallory), pp. 1-41. The MIT Press, Cambridge, MA.

Koleff, P., Gaston, K.J. \& Lennon, J.J. (2003) Measuring beta diversity for presence-absence data. Journal of Animal Ecology, 72, 367-382.

Kowarik, I. (1995) Time lags in biological invasions with regard to the success and failure of alien species. Plant invasions: general aspects and special problems (ed. by P. Pysek, K. Prach, M. Rejmànek and M. Wade), pp. 15-38. SPB Academic Publishing, Amsterdam.

Kühn, I. \& Klotz, S. (2006) Urbanization and homogenization comparing the floras of urban and rural areas in Germany. Biological Conservation, 127, 292-300.

Kühn, I. \& Klotz, S. (2007) From ecosystem invasibility to local, regional and global patterns of invasive species. Biological invasions (ed. by W. Nentwig), pp. 181-196. Springer, Berlin-Heidelberg.

Kühn, I., Brandl, R., May, R. \& Klotz, S. (2003) Plant distribution patterns in Germany - will aliens match natives? Feddes Repertorium, 114, 559-573.

Lambdon, P.W., Pyšek, P., Basnou, C. et al. (2008) Alien flora of Europe: species diversity, temporal trends, geographical patterns and research needs. Preslia, 80, 101-149.
La Sorte, F.A. \& Boecklen, W.J. (2005) Changes in the diversity structure of avian assemblages in North America. Global Ecology and Biogeography, 14, 367-378.

La Sorte, F.A. \& Pyšek, P. (2009) Extra-regional residence time as a correlate of plant invasiveness: European archaeophytes in North America. Ecology, 90, 2589.

La Sorte, F.A., McKinney, M.L. \& Pyšek, P. (2007) Compositional similarity among urban floras within and across continents: biogeographical consequences of humanmediated biotic interchange. Global Change Biology, 13, 913921.

La Sorte, F.A., McKinney, M.L., Pyšek, P., Klotz, S., Rapson, G.L., Celesti-Grapow, L. \& Thompson, K. (2008) Distance decay of similarity among European urban floras: the impact of anthropogenic activities on beta diversity. Global Ecology and Biogeography, 17, 363-371.

Legendre, P. \& Legendre, L. (1998) Numerical ecology. Elsevier Science, Amsterdam.

Leprieur, F., Beauchard, O., Hugueny, B., Grenouillet, G. \& Brosse, S. (2008) Null model of biotic homogenization: a test with the European freshwater fish fauna. Diversity and Distributions, 14, 291-300.

Levinsky, I., Skov, F., Svenning, J.C. \& Rahbek, C. (2007) Potential impacts of climate change on the distributions and diversity patterns of European mammals. Biodiversity and Conservation, 16, 3803-3816.

Lonsdale, W.M. (1999) Global patterns of plant invasions and the concept of invasibility. Ecology, 80, 1522-1536.

McKinney, M.L. (2005) Species introduced from nearby sources have a more homogenizing effect than species from distant sources: evidence from plants and fishes in the USA. Diversity and Distributions, 11, 367-374.

McKinney, M.L. \& Lockwood, J.L. (1999) Biotic homogenization: a few winners replacing many losers in the next mass extinction. Trends in Ecology and Evolution, 14, 450453.

McKinney, M.L. \& Lockwood, J.L. (2001) Biotic homogenization: a sequential and selective process. Biotic homogenization (ed. by M.L. McKinney and J.L. Lockwood), pp. 1-17. Kluwer Academic/Plenum Publishers, New York.

Manly, B.F.J. (1991) Randomization and Monte Carlo methods in biology, Chapman and Hall, London.

NatureServe (2007) NatureServe's central databases. Available at: http://www.natureserve.org/explorer/.

Niemelä, P. \& Mattson, W.J. (1996) Invasion of North American forests by European phytophagous insects - legacy of the European crucible? Bioscience, 46, 741-753.

Olden, J.D. (2006) Biotic homogenization: a new research agenda for conservation biogeography. Journal of Biogeography, 33, 2027-2039.

Olden, J.D. \& Poff, N.L. (2004) Ecological processes driving biotic homogenization: testing a mechanistic model using fish faunas. Ecology, 85, 1867-1875.

Olden, J.D. \& Rooney, T.P. (2006) On defining and quantifying biotic homogenization. Global Ecology and Biogeography, 15, 113-120. 
Olden, J.D., Poff, N.L. \& McKinney, M.L. (2006) Forecasting faunal and floral homogenization associated with human population geography in North America. Biological Conservation, 127, 261.

Pickett, S.T.A. (1989) Space-for-time substitution as an alternative to long-term studies. Long-term studies in ecology: approaches and alternatives (ed. by G.E. Likens), pp. 110-135. Springer-Verlag, New York, NY.

Pompe, S., Hanspach, J., Badeck, F., Klotz, S., Thuiller, W. \& Kühn, I. (2008) Climate and land use change impacts on plant distributions in Germany. Biology Letters, 4, 564-567.

Pyšek, P. \& Jarošík, V. (2005) Residence time determines the distribution of alien plants. Invasive plants: ecological and agricultural aspects (ed. by S. Inderjit), pp. 77-96. Birkhäuser, Basel.

Pyšek, P., Richardson, D.M., Rejmánek, M., Webster, G.L., Williamson, M. \& Kirschner, J. (2004) Alien plants in checklists and floras: towards better communication between taxonomists and ecologists. Taxon, 53, 131-143.

Qian, H. \& Ricklefs, R.E. (2006) The role of exotic species in homogenizing the North American flora. Ecology Letters, 9, 1293-1298.

Qian, H., McKinney, M.L. \& Kühn, I. (2008) Effects of introduced species on floristic similarity: comparing two US states. Basic and Applied Ecology, 9, 617-625.

R Development Core Team (2007) R: a language and environment for statistical computing. Royal Foundation for Statistical Computing, Vienna, Austria.

Rejmánek, M. (2000a) Invasive plants: approaches and predictions. Austral Ecology, 25, 497-506.

Rejmánek, M. (2000b) A must for North American biogeographers. Diversity and Distributions, 6, 208-211.

Richardson, D.M. \& Pyšek, P. (2006) Plant invasions: merging the concepts of species invasiveness and community invasibility. Progress in Physical Geography, 30, 409-431.

Richardson, D.M., Pyšek, P., Rejmánek, M., Barbour, M.G., Panetta, F.D. \& West, C.J. (2000) Naturalization and invasion of alien plants: concepts and definitions. Diversity and Distributions, 6, 93-107.

Rooney, T.P., Wiegmann, S.M., Rogers, D.A. \& Waller, D.M. (2004) Biotic impoverishment and homogenization in unfragmented forest understory communities. Conservation Biology, 18, 787-798.

Rosenzweig, M.L. (2001) The four questions: what does the introduction of exotic species do to diversity? Evolutionary Ecology Research, 3, 361-367.

Rouget, M. \& Richardson, D.M. (2003) Understanding patterns of plant invasion at different spatial scales: quantifying the roles of environment and propagule pressure. Plant invasions: ecological threats and management solutions (ed. by L.E. Child, J.H. Brock, G. Brundu, K. Brach, P. Pyšek, P.M. Wade and M. Williamson), pp. 3-15. Backhuys Publishers, Leiden.

Sax, D.F. \& Gaines, S.D. (2003) Species diversity: from global decreases to local increases. Trends in Ecology and Evolution, 18, 561-566.
Settele, J., Hammen, V., Hulme, P. et al. (2005) ALARM: assessing LArge-scale environmental risks for biodiversity with tested methods. Gaia - Ecological Perspectives for Science and Society, 14, 69-72.

Simberloff, D. (1989) Which insect introductions succeed and which fail. Biological invasions: a global perspective (ed. by J.A. Drake, H.A. Mooney, F. Di Castri, R.H. Groves, F.J. Kruger, M. Rejmánek and M. Williamson), pp. 61-75. John Wiley and Sons, New York.

Soininen, J., McDonald, R. \& Hillebrand, H. (2007) The distance decay of similarity in ecological communities. Ecography, 30, 3-12.

Thuiller, W., Lavorel, S., Araújo, M.B., Sykes, M.T. \& Prentice, I.C. (2005) Climate change threats to plant diversity in Europe. Proceedings of the National Academy of Sciences USA, 102, 8245-8250.

Tutin, T.G., Heywood, V.H., Burges, N.A., Moore, D.M., Valentine, D.H., Walters, S.M. \& Webb, D.A. (1964-1980) Flora Europaea. Cambridge University Press, Cambridge.

Van Turnhout, C.A.M., Foppen, R.P.B., Leuven, R., Siepel, H. \& Esselink, H. (2007) Scale-dependent homogenization: changes in breeding bird diversity in the Netherlands over a 25-year period. Biological Conservation, 134, 505-516.

Welch, B.L. (1938) The significance of the difference between two means when the population variances are unequal. Biometrika, 29, 350-362.

Whittaker, R.J., Willis, K.J. \& Field, R. (2001) Scale and species richness: towards a general, hierarchical theory of species diversity. Journal of Biogeography, 28, 453-470.

Williamson, M., Pyšek, P., Jarošík, V. \& Prach, K. (2005) On the rates and patterns of spread of alien plants in the Czech Republic, Britain, and Ireland. Ecoscience, 12, 424-433.

Williamson, M., Dehnen-Schmutz, K., Kühn, I., Hill, M., Klotz, S., Milbau, A., Stout, J. \& Pyšek, P. (2009) The distribution of range sizes of native and alien plants in four European countries and the effects of residence time. Diversity and Distributions, 15, 158-166.

\section{SUPPORTING INFORMATION}

Additional Supporting Information may be found in the online version of this article:

Figure S1 Geographical extent of plant data (Aitoff World Projection).

Figure S2 Geographical extent of vertebrate data (Aitoff World Projection).

Figure S3 $\beta_{\text {sim }}$ dissimilarity of all plant assemblages versus geographical distance in $\mathrm{km}$ and climatic dissimilarity, based on Euclidean distance of five averaged, standardized climatic variables.

Figure S4 $\beta_{\text {sim }}$ dissimilarity of native and non-native plant species assemblages versus geographical distance in North America and Europe. 
Figure S5 $\beta_{\text {sim }}$ dissimilarity of all vertebrate species assemblages versus geographical distance in $\mathrm{km}$ and climatic dissimilarity, based on Euclidean distance of five averaged, standardized climatic variables

Table S1 Numbers of native and non-native species by continent and origin status (native and different groups of non-natives).

Appendix S1 Geographical extent of the vascular plant and vertebrate data.

Appendix S2 Species numbers and correlations of species dissimilarities and climatic or geographic distance, respectively. 